\title{
The role of the coastal oceans on the seasonal mean air temperature in Argentina
}

\author{
Paula Carolina OLIVERI ${ }^{1 *}$ and Marcela Hebe GONZÁLEZ ${ }^{1,2}$ \\ ${ }^{1}$ Departamento de Ciencias de la Atmósfera y los Océanos, Facultad de Ciencias Exactas y Naturales, Universidad \\ de Buenos Aires, Ciudad Universitaria, Intendente Güiraldes 2160, Pabellón 2, Piso 2, Ciudad Autónoma de Buenos \\ Aires C1428EGA, Argentina. \\ ${ }^{2}$ Centro de Investigaciones del Mar y la Atmósfera, Consejo Nacional de Investigaciones Científicas y Técnicas, \\ Universidad de Buenos Aires, Ciudad Universitaria, Intendente Güiraldes 2160, Pabellón 2, Piso 2, Ciudad Autónoma \\ de Buenos Aires C1428EGA, Argentina. \\ *Corresponding author; email: poliveri@at.fcen.uba.ar
}

Received: December 7, 2018; accepted: February 4, 2020

\begin{abstract}
RESUMEN
El objetivo de este trabajo es detectar la influencia de la temperatura de superficie del mar (TSM) de las zonas costeras de los océanos Atlántico y Pacífico, sobre la temperatura media estacional en Argentina. Para ello se consideró una región de estudio delimitada por $30-90^{\circ} \mathrm{O}$ y $20-60^{\circ} \mathrm{S}$. Se obtuvieron patrones de variabilidad interanual de TSM estacional (de verano e invierno) a través de análisis de componentes principales (ACP) en modo T. Se calcularon correlaciones lineales entre las series de tiempo derivadas de este método y las de temperatura media simultánea pertenecientes a estaciones meteorológicas de Argentina. Algunos de los modos de variabilidad obtenidos mostraron relación con la temperatura media en gran parte del territorio argentino. Para evaluar la predictibilidad de la temperatura media utilizando dichos modos, se realizaron correlaciones desfasadas una estación. Los resultados mostraron un buen grado de predictibilidad para la temperatura de primavera a partir de los modos de variabilidad de TSM de invierno, pero para la temperatura de otoño no se encontró ninguna relación.
\end{abstract}

\begin{abstract}
This work aimed to detect the influence of the sea surface temperature (SST) of coastal Atlantic and Pacific oceans on the seasonal mean air temperature in Argentina. The study region was delimited by $30-90^{\circ} \mathrm{W}$ and $20-60^{\circ} \mathrm{S}$. Patterns of interannual variability of seasonal (summer and winter) SST were obtained through principal component analysis (PCA) in the T-mode. Linear correlations between time series derived from this method and the simultaneous mean air temperature series from weather stations were performed. Some of the variability modes obtained showed a relationship with mean air temperature over a large portion of Argentina. Lagged-by-one-season correlations were also made to assess the predictability of the mean temperature employing these modes. Results showed a reasonable degree of predictability in spring temperatures using winter SST variability modes, but for autumn temperatures no relationship was found.
\end{abstract}

Keywords: Sea surface temperature, mean air temperature, interannual variability, oceans. 


\section{Introduction}

Mean air temperature (from now on mean temperature), has a high impact on electric power generation, which is one of the most important economic activities in Argentina, as it affects gas consumption directly (Gil et al., 2005). Considering this impact, it is relevant to analyze the interannual variability of atmospheric temperature, for which it is necessary to know the influence of global and regional factors. It is known that there is a strong relationship between El Niño Southern Oscillation (ENSO) phenomenon and mean temperature in Argentina, for instance, positive temperature anomalies in southern Patagonia and negative anomalies in subtropical latitudes are observed during the preceding winter of a positive ENSO phase. Also, these positive anomalies extend north of Buenos Aires Province during the preceding spring of a positive phase. Opposite patterns are observed during winter and spring of the same year of a warm ENSO event (Kiladis and Díaz, 1989).

Rusticucci et al. (2003) found that seasonal occurrence of cold and warm events in Argentina, defined by daily extreme temperatures, are related to the cooling and warming of coastal waters of the South Atlantic and South Pacific oceans. According to their study, there is a fair degree of predictability of these events based on the Atlantic and Pacific sea surface temperature (SST), especially in winter, with higher correlations with the Atlantic than with the Pacific Ocean, as the Andes represent a significant orographic barrier. Barrucand et al. (2008) observed the most significant association with the Atlantic SST of coastal zones in the frequency of warm events in the central-east and northeast of Argentina. The present work aimed to find the relationship between the SST of the Atlantic and Pacific coastal oceans, and the mean inland temperatures in Argentina.

This paper is organized as follows: section 2 details the data employed in this study, section 3 determines the variability patterns of SST, section 4 analyzes the relationship between these patterns and mean temperature, and section 5 presents the conclusions.

\section{Data}

Monthly SST data from the ERA-Interim reanalysis (Dee et al., 2011) of the European Centre of Medi-
um-Range Weather Forecast, with $0.75^{\circ}$ resolution (downloaded from http://www.ecmwf.int/en/forecasts/datasets) were used to obtain seasonal averages for the period 1980-2015. Seasons were defined as DJF (summer), MAM (autumn), JJA (winter) and SON (spring). These averages were performed over a study region delimited by $20-60^{\circ} \mathrm{S}$ and $30-90^{\circ} \mathrm{W}$, to analyze the interannual variability of the coastal SST values, and to detect its contribution to mean seasonal temperature in Argentina.

The National Meteorological Service of Argentina provided monthly mean temperature data from 67 weather stations (Fig. 1). Seasonal averages from DJF 1980 until DJF 2015 were obtained from these stations (observations were not available beyond March 2015).

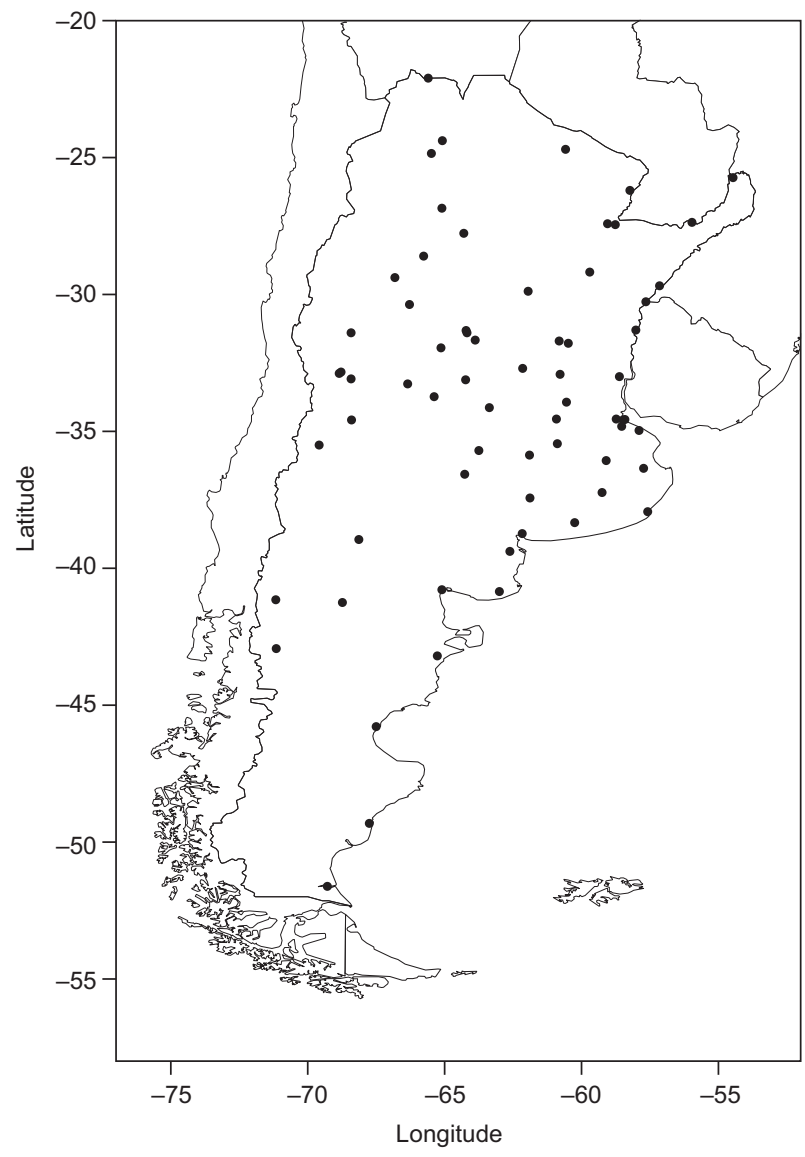

Fig. 1. Study area. Black dots show the weather stations locations. The longitudinal extent of this study is broader (90 to $30^{\circ} \mathrm{W}$ ). 
Composites of $850 \mathrm{hPa}$ wind anomaly from the NCEP/NCAR reanalysis (Kalnay et al., 1996) provided by the NOAA-ESRL Physical Sciences Division (from their webiste at http://www.esrl.noaa.gov/psd/) were used. For these data, the employed climatology period was from 1981 to 2010 .

\section{Variability patterns of seasonal SST}

Interannual variability of summer and winter SST was studied through principal component analysis (PCA) derived patterns on T-mode (Preisendorfer, 1988). In this mode, the variables are the spatial fields defined by $m$ grid points, at each of the $n$ times. In this work spatial fields of seasonal (summer or winter) SST anomalies were considered.

The study region was delimited by $30-90^{\circ} \mathrm{W}$ and $20-60^{\circ} \mathrm{S}$, with a $0.75^{\circ}$ spacing between grid points, comprising a total number of $4455 \mathrm{~m}$ points. The analyzed period from 1980-2015 (i.e., $n=36$ years) comprises 36 input variables. If the standardized (by the mean and standard deviation of each column) data matrix $X_{S}$ is the input matrix of PCA, the three output arrays are (Compagnucci and Salles, 1997):

1. $D(n x n)$ a diagonal matrix whose entries are the ordered eigenvalues $\lambda_{j}$ of the correlation matrix $R=\frac{1}{\mathrm{~m}-1} X_{S}^{T} X_{S}$, where $j=1, \ldots, r$ and $r \leq \min (m, n)$.

2. $F(n x n)$ a component loading matrix $F=U D^{1 / 2}$ where $U(n x n)$ is the eigenvector matrix of $R$.

3. $Z_{S}(m x n)$ a principal components matrix $Z_{S}=$ $X_{S} U D^{-1 / 2}\left(D^{-1 / 2}\right.$ is the inverse of $\left.D^{1 / 2}\right)$.

The new variables, now called principal components (PCs), are the columns of $Z_{s}$ and they are the spatial patterns in the T-mode, while $F$ columns or PC component loadings (PCLs) are the time series. PCLs are conformed by correlation coefficients between the original variables and the corresponding principal component. $F$ has two interesting properties: the sum of the squared loadings of each component equals its respective eigenvalue, and similarly, the sum of the squared entries of each variable equals its respective variance (Carroll et al., 1997), which is equal to 1 for standardized variables. This means that the sum of all the eigenvalues equals the total variance and so the i-th PC accounts for $\lambda_{i} / \sum_{j=1}^{r} \lambda_{j}$ of the total variance.

In this work, the PCA technique was applied through singular value decomposition (SVD) from which the same arrays $D, F$ and $Z_{S}$ can be obtained (Green, 1978; Mestas-Núñez, 2000; Compagnucci et al., 2001; Compagnucci and Richman, 2008). Spatial patterns and time series given by PC and PCL, respectively, represent interannual variability patterns of summer (section 3.1) and winter (section 3.2) SST.

\subsection{Summer patterns}

A subjective (non-statistically inferred) truncation criteria was applied to select the optimum number of PCs. To do so, the PCs must explain an important proportion of total variance and also show spatial patterns with physical meaning. The truncation cutoff for the principal components was taken following a scree test. This test consists of identifying a point at the eigenvalue spectrum plot $\left(\lambda_{i}\right.$ vs. $\left.i\right)$, which separates a steeply sloping portion to the left, and a more shallowly sloping portion to the right. The principal component number at which the separation occurs is taken as the truncation cutoff. For the summer patterns, this cutoff was at seven PCs. Similarly, according to the Kaiser criterion (PCs whose eigenvalue is greater than 1), eight PCs should have been retained (Wilks, 2006). The explained variance for the first eight PCs is shown in Table I, accounting for more

Table I. Percentage of explained variance for summer (DJF).

\begin{tabular}{lcccccccc}
\hline & PC 1 & PC 2 & PC 3 & PC 4 & PC 5 & PC 6 & PC 7 & PC 8 \\
\hline $\begin{array}{l}\text { Explained } \\
\text { variance (\%) }\end{array}$ & 22.98 & 19.77 & 11.11 & 7.75 & 6.68 & 6.31 & 3.43 & 3.26 \\
\hline $\begin{array}{l}\text { Cumulative } \\
\text { explained } \\
\text { variance (\%) }\end{array}$ & 22.98 & 42.75 & 53.86 & 61.61 & 68.29 & 74.6 & 78.03 & 81.29 \\
\hline
\end{tabular}


than $80 \%$ of the total variance altogether and $60 \%$ if only the first four are considered. Spatial patterns of the SST anomaly given by the first four PCs are shown in Figure 2 and described below:

- PC 1 showed a warm center over the Atlantic and a cold center over the Pacific off the southern Patagonian coast (Fig. 2a).

- PC 2 consisted of warmer temperature anomalies in the Atlantic Ocean which extended from southern Brazil to the coastal waters of Uruguay and Buenos Aires, south of which colder temperatures were observed. Over the Pacific Ocean SST anomalies were warmer than those found on PC1, but less warm than the Atlantic anomalies (Fig. 2b).

- PC 3 showed warmer anomalies over the Pacific Ocean, off the north coast of Chile, and over the Atlantic, off the coast of Buenos Aires and Patagonia. Further out from the coast, colder anomalies were seen off the coast of Chile and Argentina (Fig. 2c).

- PC 4 was characterized by a cold center over the Pacific Ocean, off the southern Chilean coast. Over the Atlantic cooling off the Patagonian coast and warming off the Buenos Aires coast was observed. Further east, the pattern was unclear (Fig. 2d).

As the pattern represented by PC 4 had an important spatial variability, an analysis was made only for the first three PCs, which accounted for $23 \%, 19.8 \%$ and $11.1 \%$ of the total variance, respectively $(53.9 \%$ in total). The time series represented by the first three PCLs are displayed in Figure 3. Each of them shows (a)

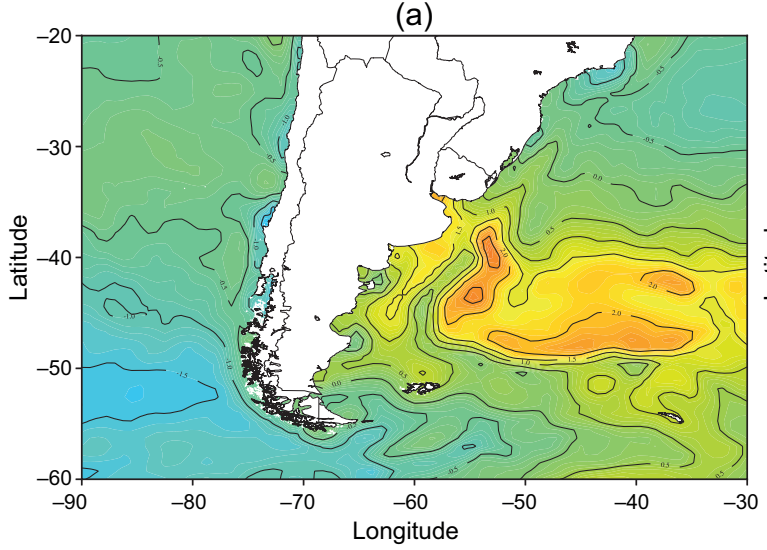

(c)

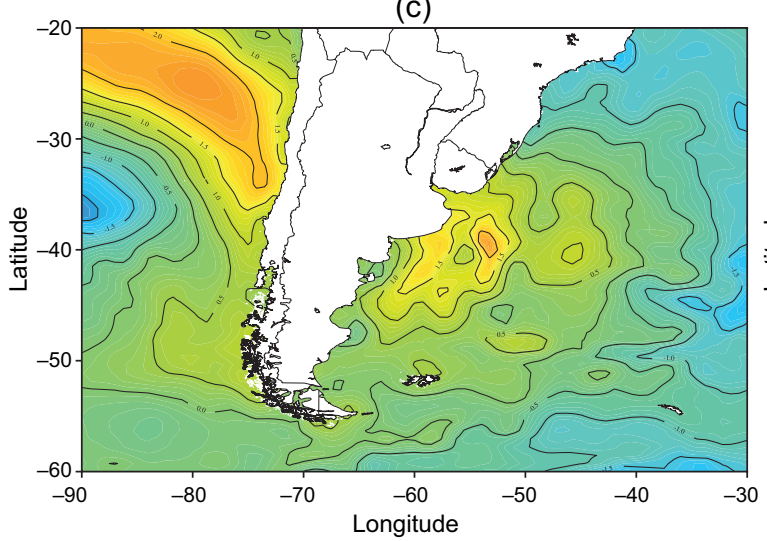

(b)



(d)

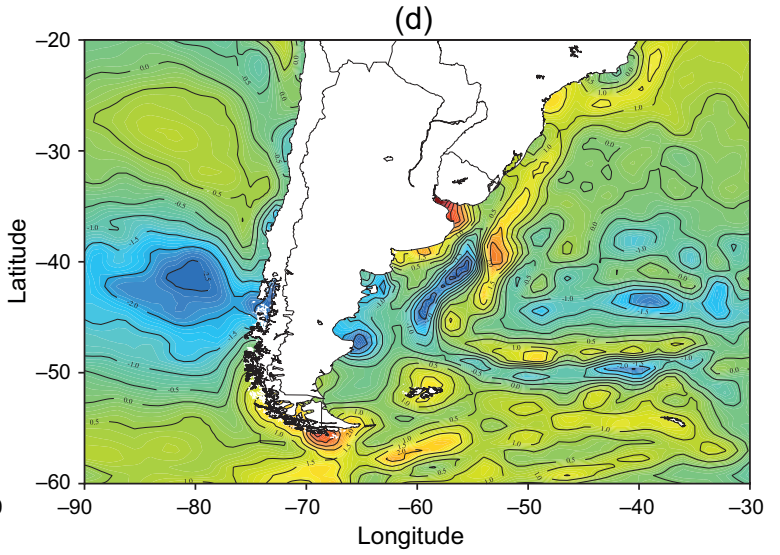



Fig. 2. Summer (DJF) principal components: (a) PC 1, (b) PC 2, (c) PC 3 and(d) PC 4. 
(a)

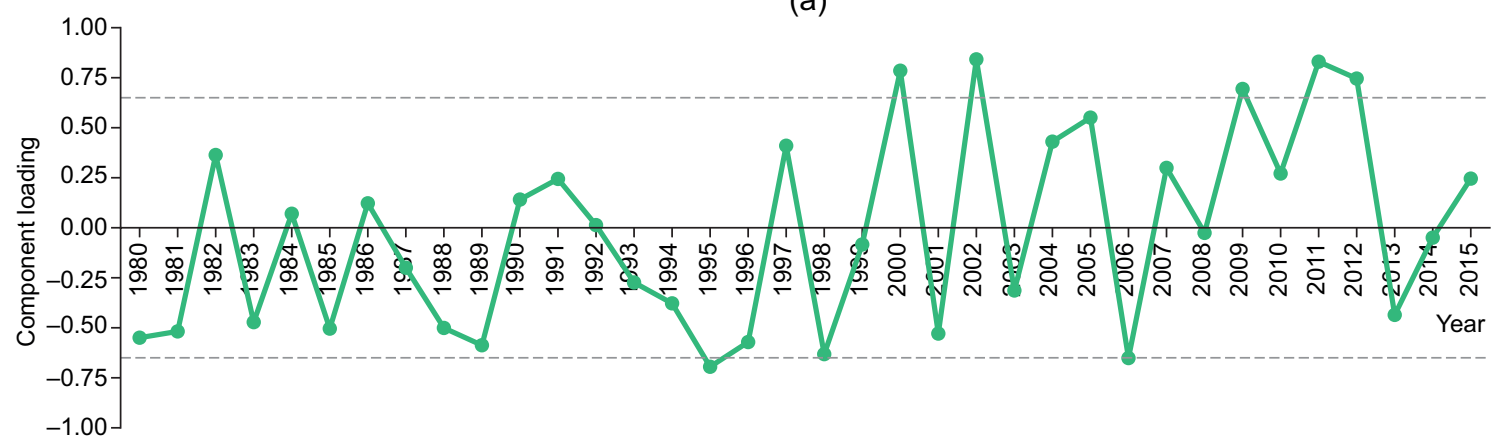

(b)

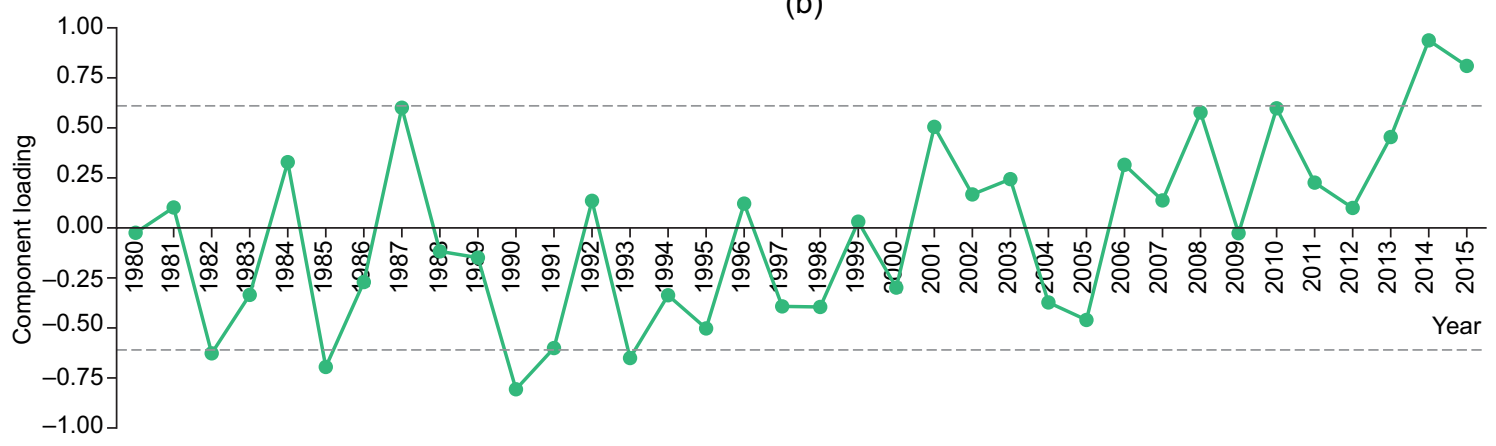

(c)

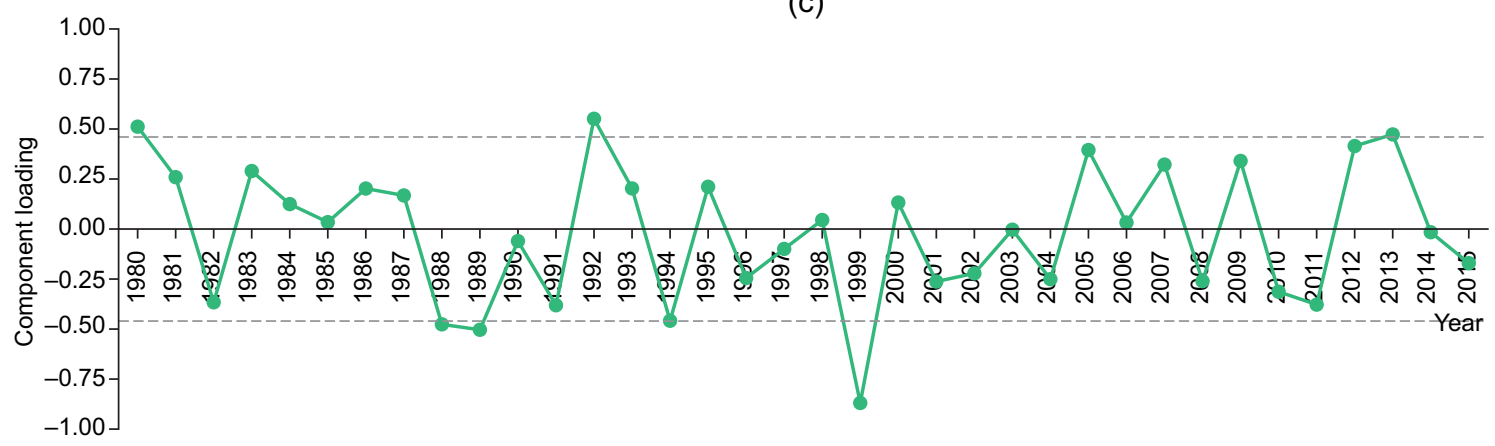

Fig. 3. Summer (DJF) PC loadings: (a) PCL 1, (b) PCL 2 and (c) PCL 3.

the correlation value between the corresponding PC and the summer SST anomaly field of each year of the considered period. The most highly correlated years of each PC were defined as follows: the years whose correlation value was greater than a cutoff value, given by the mean of the absolute value of all the correlations plus a standard deviation (see Table II).

\subsection{Winter patterns}

Based on the scree test, the number of winter PCs that should have been retained was seven. Eigenvalues greater than 1 corresponded only to the first eight PCs. The explained variance by the first eight PCs is shown in Table III, which accounted for $75 \%$ of the total variance, and almost $60 \%$ only considering the first four components. The spatial patterns of SST anomalies given by the first four PCs are shown in Figure 4, and described below.

- PC 1 showed maximum variability over the Atlantic Ocean, with the main warm center extending to the northeast, from Patagonia to southern Brazil. Off the coast of Buenos Aires, a warm center in the north and a cold one in the south were recorded. In between these centers, a cold center was observed reaching Patagonia, which extended 
Table II. Best correlated years between summer SST anomalies and the first three PCs. Cutoff correlation values are shown.

\begin{tabular}{lccc}
\hline & PC 1 & PC 2 & PC 3 \\
\hline $\begin{array}{l}\text { Cutoff } \\
\text { value }\end{array}$ & 0.65 & 0.61 & 0.46 \\
\hline $\begin{array}{l}\text { Positive } \\
\text { correlation }\end{array}$ & $2000,2011,2012$ & 2014,2015 & $1980,1992,2013$ \\
\hline $\begin{array}{l}\text { Negative } \\
\text { correlation }\end{array}$ & 1995,2006 & 1982,1985, & $1988,1989,1999$ \\
\hline
\end{tabular}

Table III. As in Table I, but for winter (JJA).

\begin{tabular}{lcccccccc}
\hline & PC 1 & PC 2 & PC 3 & PC 4 & PC 5 & PC 6 & PC 7 & PC 8 \\
\hline $\begin{array}{l}\text { Explained } \\
\text { variance (\%) }\end{array}$ & 28.90 & 12.92 & 9.59 & 6.58 & 6.20 & 4.75 & 3.28 & 3.08 \\
\hline $\begin{array}{l}\text { Cumulative } \\
\text { explained } \\
\text { variance (\%) }\end{array}$ & 28.90 & 41.82 & 51.41 & 57.99 & 64.19 & 68.94 & 72.22 & 75.30 \\
\hline
\end{tabular}

eastwards. South of $50^{\circ} \mathrm{S}$, cooling was seen over the Atlantic Ocean. In addition, the coastal waters of the Pacific Ocean exhibited slightly cold anomalies (Fig. 4a).

- PC 2 was characterized by warming over the Pacific Ocean with a maximum to the north, and a cold center over the Atlantic Ocean some distance away from the northern Patagonia coast. There were other cold centers over the ocean, south of Patagonia (Fig. 4b).

- PC 3 showed a cold center off the coast of Buenos Aires, and a warm center east of it, which reached southern Brazil. East of these main centers, the ocean was warm to the north and mostly cold to the south. The coastal Pacific presented weak anomalies (Fig. 4c).

- PC 4 exhibited a cold center over the subtropical Pacific and slight warming along the length of the nearshore coastal waters, while the Atlantic showed positive anomalies over its center, especially off the Buenos Aires coast. Cooling to the north and the south of this area was recorded, which was stronger in the south (Fig. 4d).

The analysis of the next sections includes the four first PCs, as all of them showed clear spatial patterns and accounted for $58 \%$ of the total variance $(28.9 \%$ by PC $1,12.9 \%$ by PC $2,9.6 \%$ by PC 3 , and $6.6 \%$ by PC 4). The time series represented by the first four PCLs are displayed in Figure 5. Cutoff correlation value and most highly correlated years were chosen using the same criterion as for summer PCs (Table IV).

\section{Relationships between variability patterns of SST and seasonal mean temperature}

Linear correlations between PCLs from interannual variability modes of seasonal (summer and winter) SST and simultaneous series of mean temperatures were calculated, to find a relationship between both variables. To evaluate the predictability of seasonal mean temperature, lagged-by-one-season correlations were also performed (i.e., summer PCLs with autumn temperature and winter PCLs with spring temperature).

The significance of Pearson correlation coefficient was tested by a two-tailed t-test with a confidence level of $95 \%$. The test statistic used was $T=\frac{R \sqrt{n-2}}{1-R^{2}}$ and $n-2$ the degrees of freedom (Devore, 2011). The degree of freedom for correlations that involved summer series was 34 , whereas for autumn, winter and spring it was 33 . Therefore, in all these cases, 
(a)

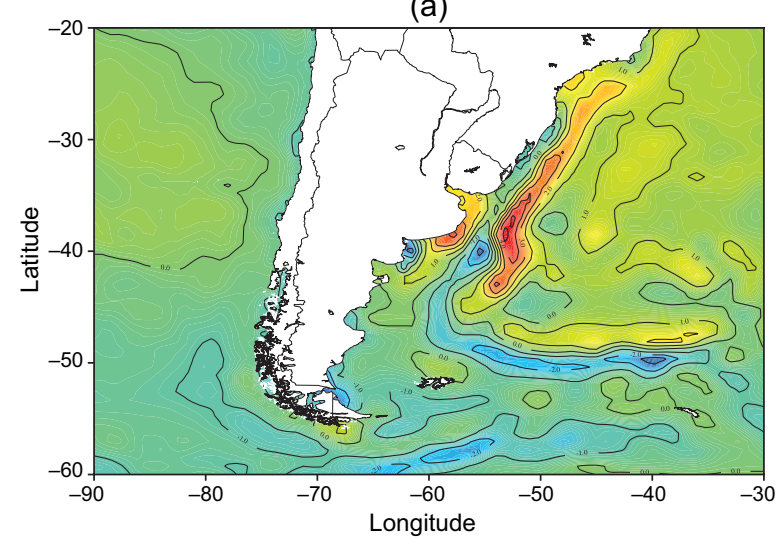

(c)



(b)

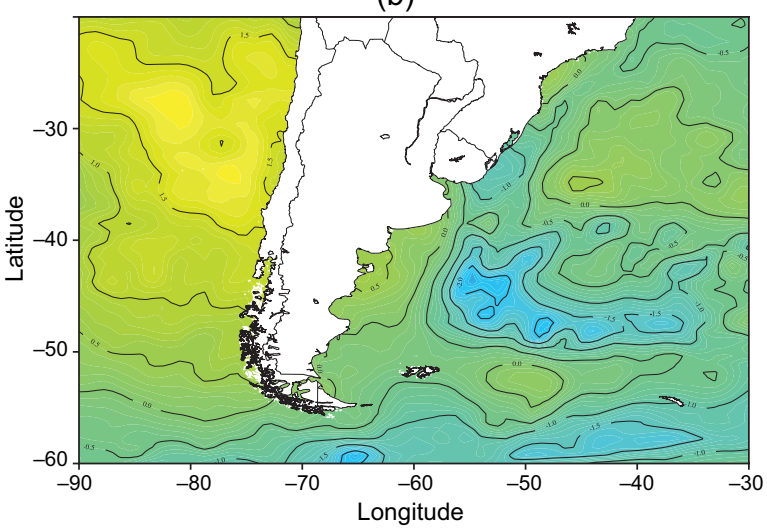

(d)

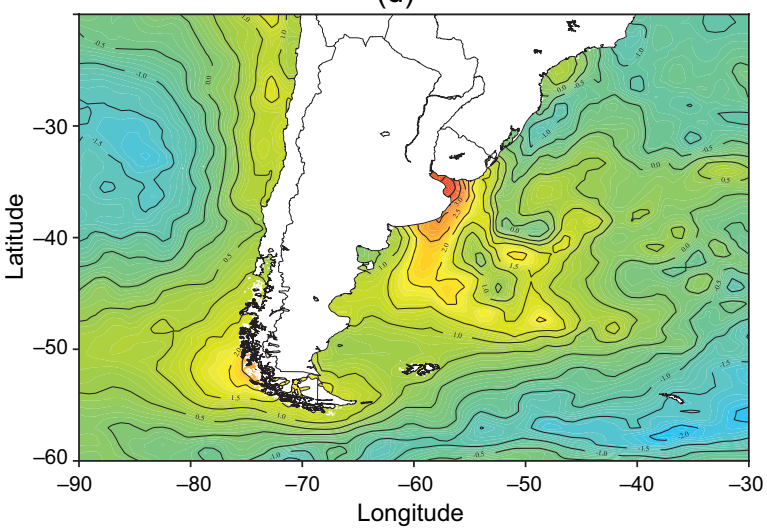

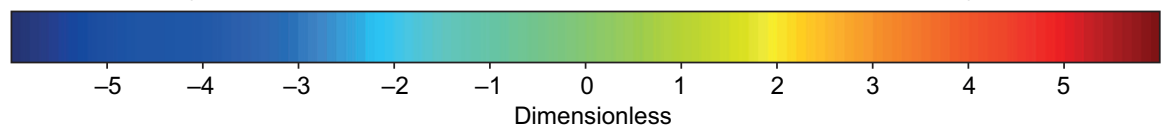

Fig. 4. As in Figure 2, but for winter (JJA).

a correlation coefficient of 0.34 was required for a significant linear relationship with a confidence level of $95 \%$. Correlation distributions were performed by interpolating correlation values using a Cubic Spline method. Obtained results are discussed in section 4.1 for SST variability patterns of both summer (section 4.1.1) and winter (section 4.1.2). In section 4.2 some processes which would connect variability patterns of SST and simultaneous seasonal mean temperature of Argentina, are analyzed.

\subsection{Variability patterns of SST and mean tempera- ture}

\subsubsection{Summer}

The first variability pattern of summer SST did not show association with simultaneous mean temperature in Argentina, since PCL 1 was significantly correlated with mean temperature series only at an isolated meteorological station in Patagonia (Comodoro Rivadavia Aero: 87860). The second pattern (the second pattern but with opposite sign anomalies) showed association with simultaneous warm (cold) anomalies over a large area of northern and west-central Argentina (Fig. 6 a). Correlation values between PCL2 and the simultaneous mean temperature series were significant in almost half of all meteorological stations. This suggests that warm (cold) anomalies over the coastal Atlantic, north of Buenos Aires, and cold (warm) to the south, and the warm (cold) anomalies over the Pacific, at the center of the study region, contribute to warmer (colder) than normal summers at northern and west-central Argentina. The third pattern (the third pattern but with opposite sign anomalies) was related to positive (negative) anomalies of simultaneous mean temperature just over a small area of northeastern Argentina (Misiones 


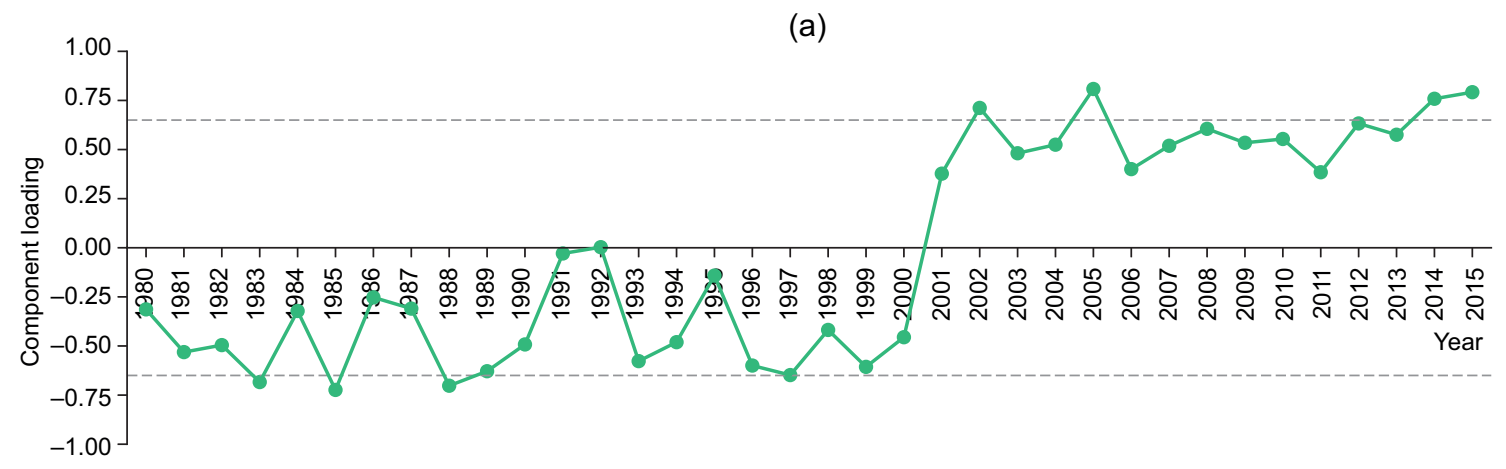

(b)

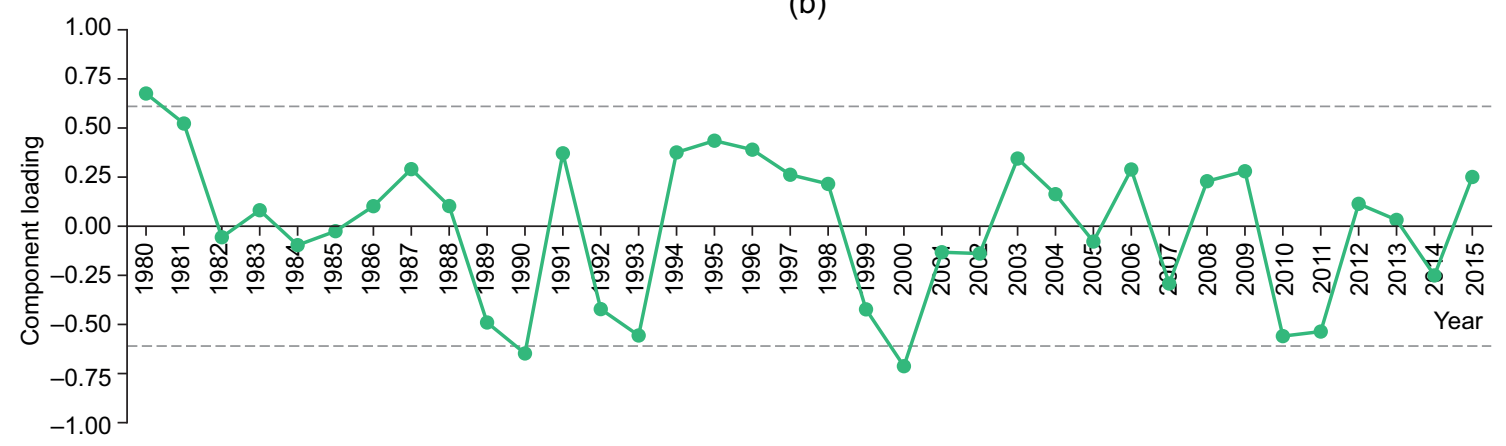

(c)

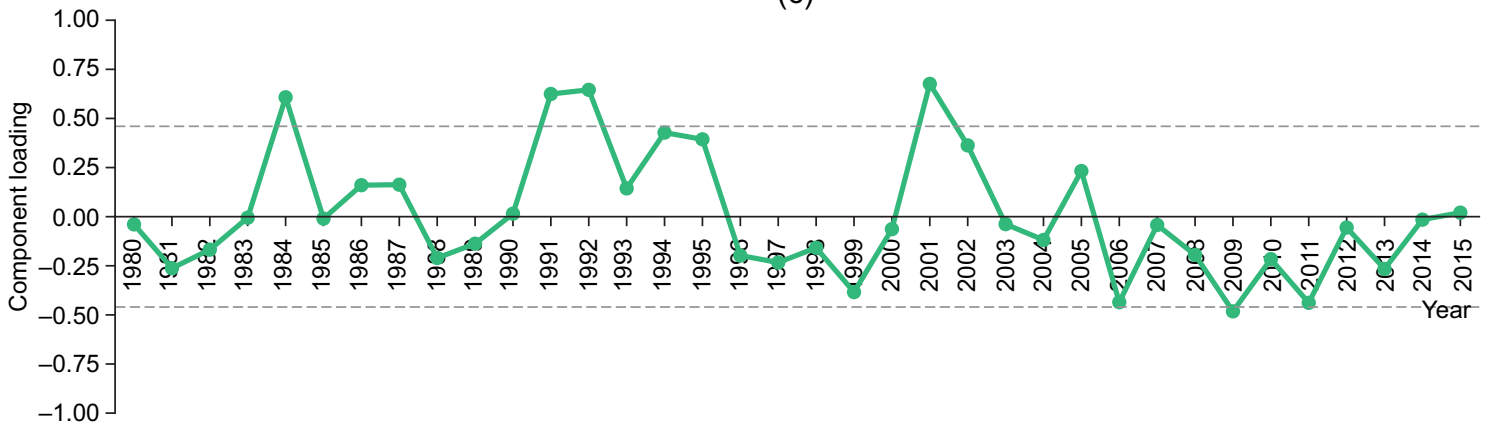

(d)

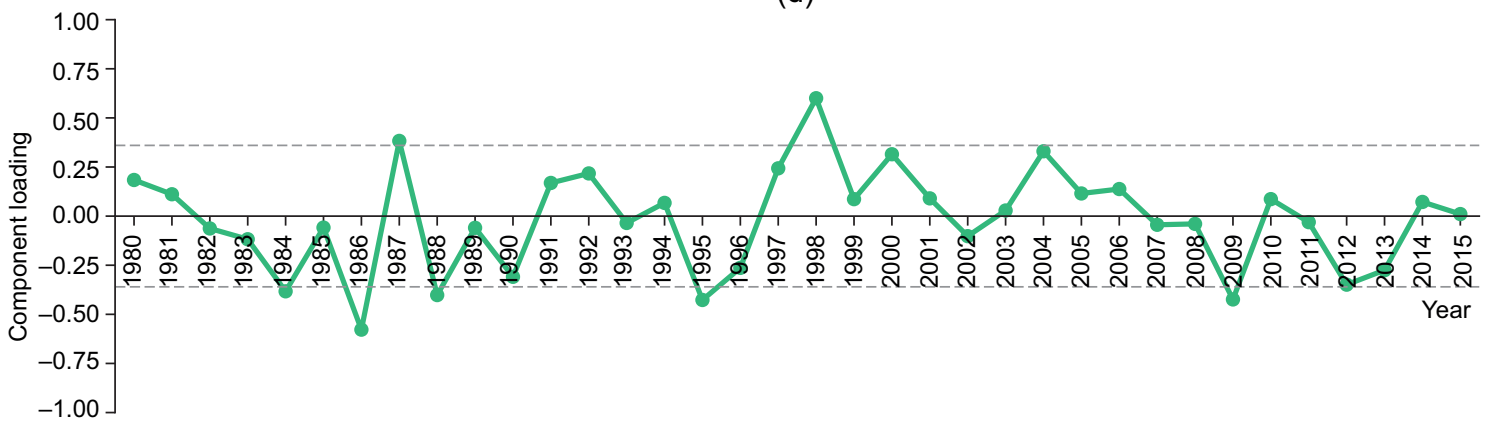

Fig. 5. As in Figure 3, but for winter (JJA) and (d) PCL 4.

province). Lagged correlations (not shown) showed a poor relationship between summer SST variability modes and autumn mean temperature.

\subsubsection{Winter}

The first variability pattern of winter SST (the first pattern but with opposite sign anomalies) showed 
Table IV. As in Table II, but for winter (JJA).

\begin{tabular}{lcccc}
\hline & PC 1 & PC 2 & PC 3 & PC 4 \\
\hline Cutoff value & 0.69 & 0.49 & 0.43 & 0.36 \\
\hline Positive correlation & 2002,2005, & 1980,1981 & 1984,1991, & 1987,1998 \\
& 2014,2015 & & 1992,2001 & \\
\hline Negative correlation & 1985,1988 & $1989,1990,1993$, & 2006,2009, & $1984,1986,1988$, \\
& & $2000,2010,2011$ & 2011 & 1995,2009 \\
\hline
\end{tabular}

association with simultaneous warm (cold) anomalies in the north and center-west of Argentina (Fig. 6b). This indicates that an anomalously warm (cold) Atlantic Ocean close to the north of Buenos Aires and cold (warm) to the south, may be accompanied by a warmer (colder) winter than normal in northern and west-central Argentina. This relationship is maintained until the following spring according to the lagged correlation and, in this case, the area with significant values was larger than the simultaneous one (Fig. 6c). This could mean that there is a good degree of predictability of mean temperature from the first variability pattern of winter SST.

The correlation distribution corresponding to PCL 2 and the simultaneous mean temperature series had no significant areas, so the second variability pattern of winter SST could not be related to winter mean temperature. The correlation value resulted significant only at an isolated meteorological station in northeastern Argentina (Iguazú Aero: 87097).

Besides the first pattern, the third pattern (the third pattern but with opposite sign anomalies) also showed a good relation to the simultaneous mean temperature in Argentina. It showed association with cold (warm) simultaneous mean temperature anomalies in most of Patagonia and the south of Buenos Aires province (Fig. 6d). This suggests that a mostly cold (warm) southern Atlantic Ocean, with a pronounced cooling (warming) near Buenos Aires coast and warm (cold) anomalies near the southern coast of Brazil, which extend to south, east of Río de la Plata, promote anomalously cold (warm) winters in Argentinian Patagonia.

PCL 4 was positively correlated with simultaneous mean temperature series of all the meteorological stations considered. Nonetheless, these correlations resulted significant just over the east of Buenos Aires province, and only in this area, the fourth variability pattern of winter SST (the fourth pattern but with opposite sign anomalies) could be associated with positive (negative) anomalies of mean temperature.

Besides the first variability mode, the other winter variability modes did not show an important relationship with spring mean temperature.

\subsection{Hypotheses that may explain the relationship between variability patterns of SST and seasonal mean temperature}

Additional analysis was conducted for those PCs whose associated PCLs showed the most important significant correlations with simultaneous seasonal mean temperature, to find processes which may lead to this relationship. Seasonal composites of the $850 \mathrm{hPa}$ wind anomaly of the best correlated years (according to the criterion explained in section 3) were studied, taking separately those years which were positively correlated (hereafter "+ Years") and those which were negatively correlated (hereafter " Years"). Thus, in + Years the SST anomaly patterns were similar to the corresponding PC and in - Years the patterns were similar to the opposite to the one displayed (i.e., cold where it is warm, etc.).

Some hypotheses about the processes which may contribute to the explanation of the observed correlations are exposed below. It is necessary to take into consideration that composite fields were performed in general with a few cases, and also that not all the correlations of + Years and - Years with the corresponding PC were equally high.

Summer PC 2 (Fig. 2b) is associated with warm anomalies over north and center-west of Argentina, as it was described above. Both subtropical high and subpolar low were intensified, leading to more intense westerlies (Fig. 7a) in the case of + Years (2014, 
(a)

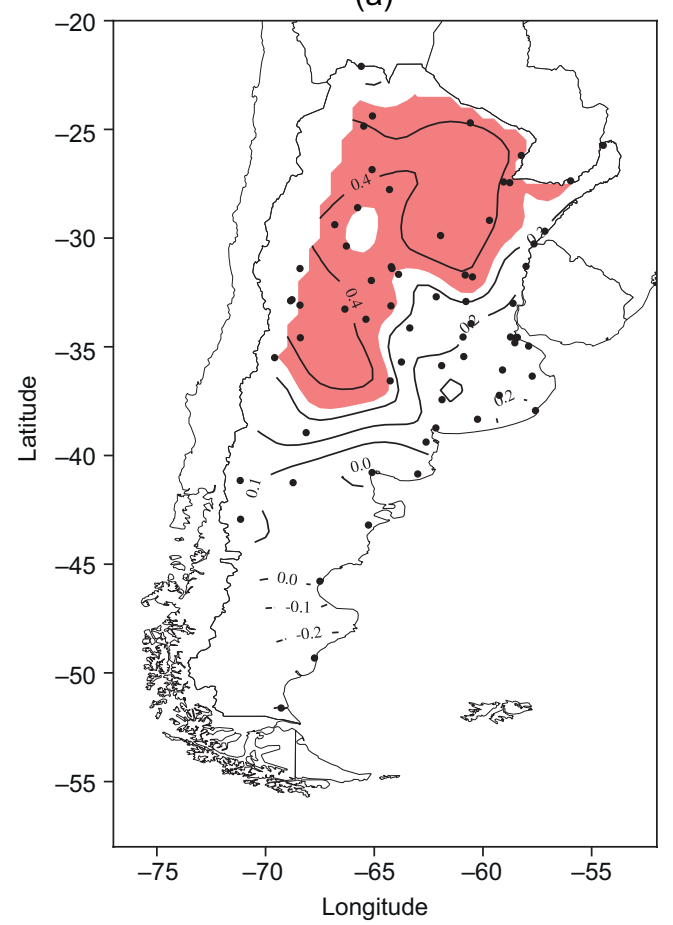

(c)

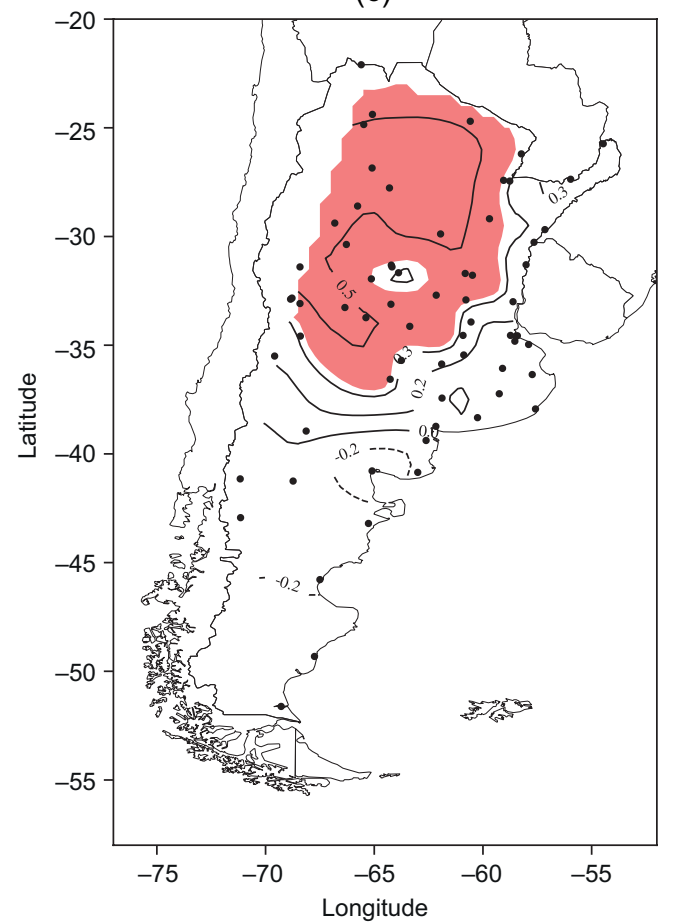

(b)

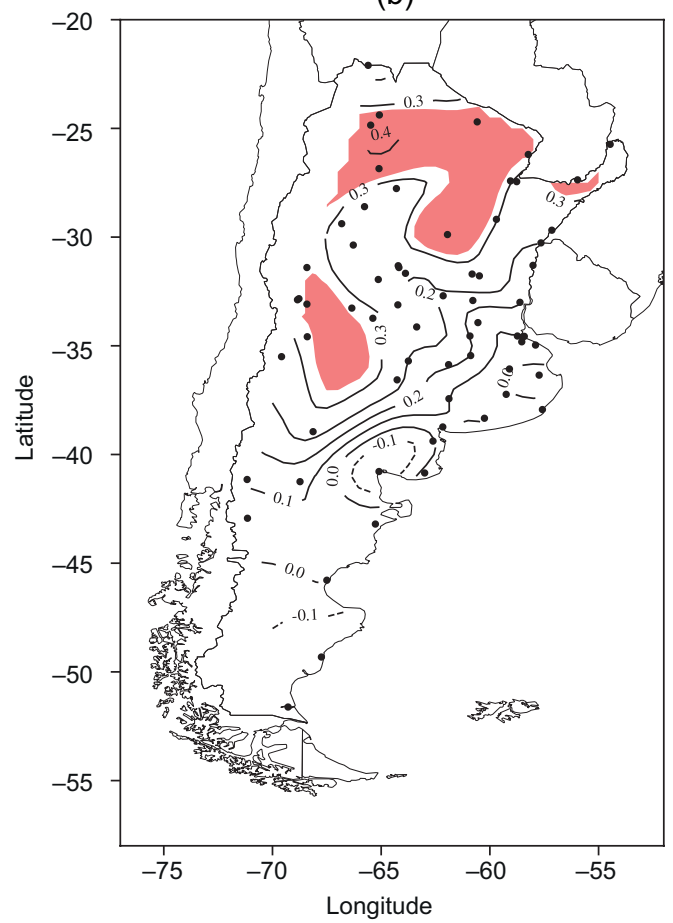

(d)

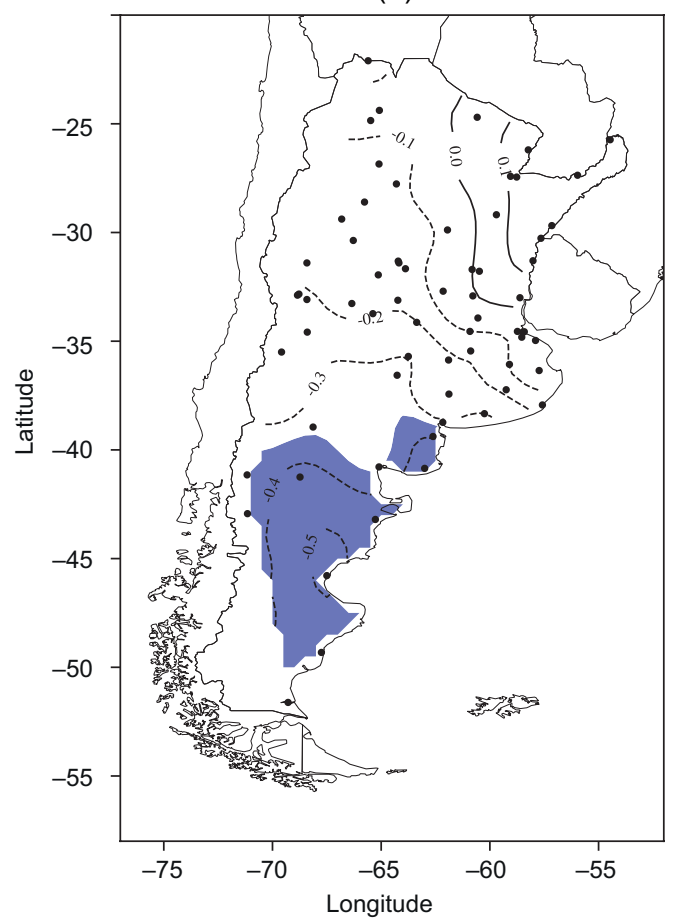

Fig. 6. Distribution of the Pearson correlation coefficient between PCLs and mean temperature series: (a) DJF PCL 2 and simultaneous series, (b) JJA PCL 1 and simultaneous series, (c) JJA PCL 1 and (d) lagged series and JJA PCL 3 and simultaneous series. Blue and red colors denote negative and positive correlations, respectively, with a significant confidence level of $95 \%$. 
(a)

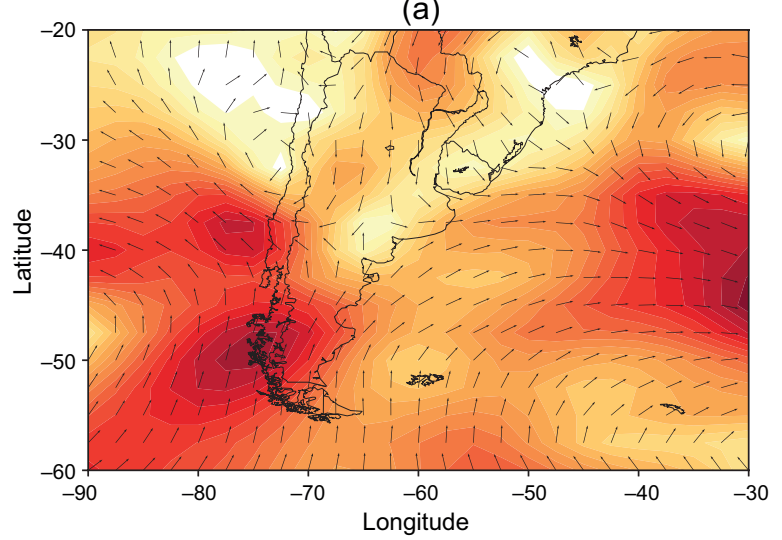

(b)



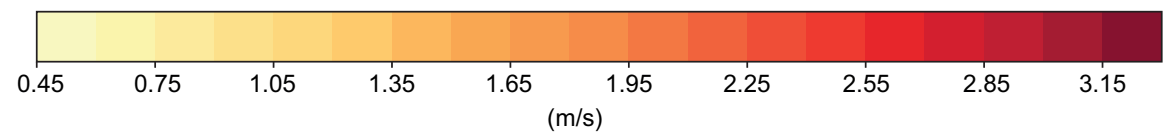

Fig. 7. Summer (DJF) composite of (a) $850 \mathrm{hPa}$ wind anomaly (m/s) of the + Years and (b) - Years defined for the summer PC 2.

2015), so it was less probable that frontal perturbations moved northward (Silvestri and Vera, 2003; Reboita et al., 2009). In summer, less frontal precipitation is associated with higher temperatures. Besides, the Atlantic Ocean was probably anomalously warm in the north because of the similarity of +Years patterns to PC 2, so the north-northeastern flow which came from the anticyclone, increased the warming, especially in northern Argentina where the northern flow (low-level jet) prevails in summer. Consequently, a relationship between this pattern and higher temperatures in northern Argentina is logical. The opposite was observed in - Years (1982, 1985, 1990, 1993), when wind anomalies showed both weaker-than-normal subtropical high and subpolar low (Fig. 7b).

Winter PC 1 (Fig. 4a) showed association with warm anomalies in northern and west-central Argentina. Air advection from the north prevailed over northern and, especially, northeastern Argentina (Fig. 8a) in the + Years $(2002,2005,2014,2015)$, (a)



(b)

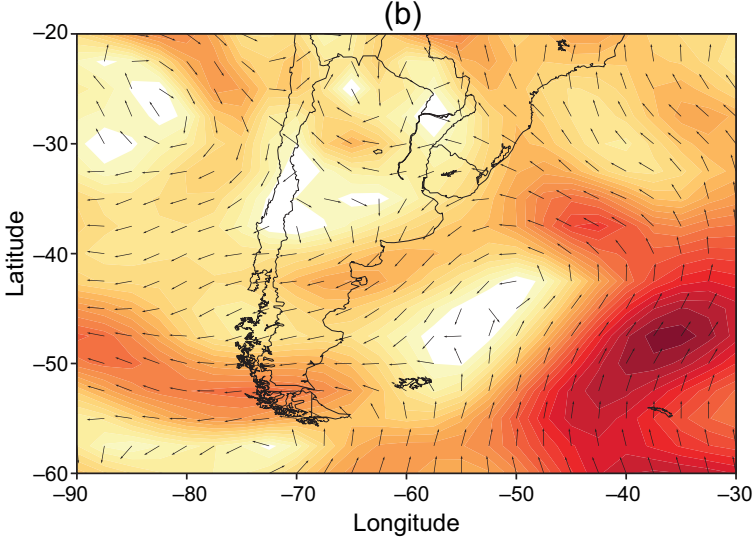

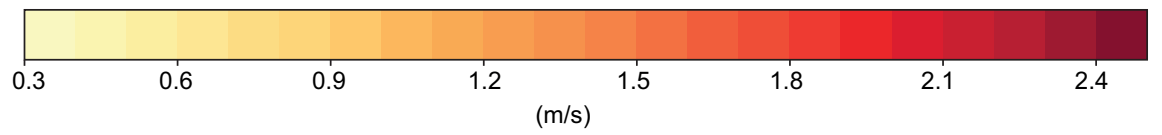

Fig. 8. As in Figure 7, but for winter (JJA) and PC 1. 
leading to higher temperatures there. This effect would have been enhanced if the Atlantic Ocean was warm in the area where the anticyclone enters the continent, which is probable since the + Years patterns were similar to PC 1. In contrast, in the Years $(1985,1988)$ wind was anomalously easterly (Fig. 8b) and came from a portion of the Atlantic that was probably cooler than normal.

Winter PC 3 (Fig. 4c) is related to cold anomalies over most of Patagonia and the south of Buenos Aires province. Easterly wind anomalies were observed in southern Argentina (Fig. 9a), reflecting an important weakening of the westerlies in + Years (1984, 1991, 1992, 2001). Because of + Years patterns similarity to PC 3, this meant enhanced possibilities of cold advection from a cooler-than-normal Atlantic Ocean towards Patagonia and, therefore, of lower-than-normal temperatures there. On the other hand, there were very slight anomalies over the Atlantic Ocean close to Patagonia in the case of - Years $(2006,2009,2011)$ composite (Fig. 9b). This effect does not seem to explain the important signal observed over Patagonia only by itself, as the SST anomalies over the nearby ocean were not so high. Probably, other factors enhanced this signal (for instance, weakened westerlies imply more fronts passing through and therefore higher cloud cover, associated with lower mean temperature).

\section{Conclusions}

Results showed a relationship between coastal oceans SST and mean temperature in Argentina. Particularly, warm (cold) anomalies over the nearby Atlantic, north of Buenos Aires and cold (warm) to the south, and the nearby Pacific anomalously warm (cold) at the center of the study region, are associated with warmer (colder) than normal summers at northern and west-central Argentina. Besides, an anomalously warm (cold) Atlantic Ocean close to the north of Buenos Aires and cold (warm) to the south contribute with warmer (colder) than normal winters in northern and west-central Argentina. This pattern also affects the following spring in the same way, but over a larger area. Also, a mostly cold (warm) southern Atlantic Ocean, with a pronounced cooling (warming) near Buenos Aires coast and warm (cold) anomalies near southern coast of Brazil which extend to south, east of Río de la Plata, are related to anomalously cold (warm) winters in Argentinian Patagonia.

Findings of this study suggested that there is a good degree of predictability of spring mean temperature from a winter SST pattern, which accounts for almost $29 \%$ of the total variance. In contrast, autumn mean temperature seems to have a poor relationship with SST summer patterns. (a)



(b)



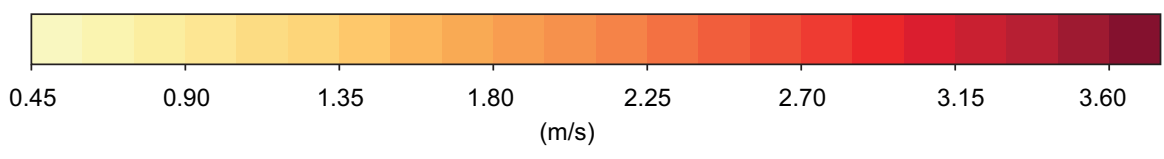

Fig. 9. As in Figure 7, but for winter (JJA) and PC 3. 


\section{Acknowledgments}

This research was supported by UBACYT 2017-2019 20020160100009BA and UBACYT Interdisciplinary 2018-2020 20620170100012BA projects. We would like to thank the NOAA-ESRL Physical Sciences Division, the European Centre of Medium-Range Weather Forecast and the National Meteorological Service of Argentina for providing the data for this research.

\section{References}

Barrucand M, Rusticucci M, Vargas W. 2008. Temperature extremes in the south of South America in relation to Atlantic Ocean surface temperature and Southern Hemisphere circulation. Journal of Geophysical Research 113, D20111. DOI: 10.1029/2007JD009026

Carroll JD, Green PE, Chaturverdi A. 1997. Mathematical tools for applied multivariate analysis. Revised edition. Academic Press, San Diego, CA, 392 pp.

Compagnucci RH, Araneo D, Canziani PO. 2001. Principal sequence pattern analysis: A new approach to classifying the evolution of atmospheric systems. International Journal of Climatology 21:197-217. DOI: $10.1002 /$ joc.601

Compagnucci RH, Richman MB. 2008. Can principal component analysis provide atmospheric circulation or teleconnection patterns? International Journal of Climatology 28:703-726. DOI: 10.1002/joc. 1574

Compagnucci RH, Salles MA. 1997. Surface pressure patterns during the year over southern South America. International Journal of Climatology 17:635-653. DOI: 10.1002/(SICI)1097-0088(199705)17:6<635:: AID-JOC81>3.0.CO;2-B

Dee DP, Uppala SM, Simmons AJ, Berrisford P, Poli P, Kobayashi S, Andrae U, Balmaseda MA, Balsamo G, Bauer P, Bechtold P, Beljaars ACM, van de Berg L, Bidlot J, Bormann N, Delsol C, Dragani R, Fuentes M, Geer AJ, Haimberger L, Healy SB, Hersbach H, Hólm EV, Isaksen L, Kållberg P, Köhler M, Matricardi M, McNally AP, Monge-Sanz BM, Morcrette J-J, Park B-K, Peubey C, de Rosnay P, Tavolato C, Thépaut J-N, Vitart F. 2011. The ERA-Interim reanalysis: Configuration and performance of the data assimilation system. Quarterly Journal of the Royal Meteorological Society 137: 553-597. DOI: 10.1002/qj.828
Devore JL. 2011. Probability and statistics for engineering and the sciences. 8th ed. Cengage Learning, Boston, MA, 776 pp.

Gil S, Duperron L, Ruggero R. 2005. Evaluación del plan de ahorro de consumo de gas natural en Argentina. Pretrotecnia (revista del Instituto Argentino del Petróleo y del Gas), XLVI, 3:48-54.

Green PE. 1978. Analyzing multivariate data. The Dryden Press, Hinsdale, IL.

Kalnay E, Kanamitsu M, Kistler R, Collins W, Deaven D, Gandin L, Iredell M, Saha S, White G, Woollen J, Zhu Y. 1996. The NCEP/NCAR 40-year reanalysis project. Bulletin of the American Meteorological Society $77: 437-472$.

DOI: $10.1175 / 1520-0477(1996) 077<0437$ :TNYRP $>2.0 . \mathrm{CO} ; 2$

Kiladis GN, Díaz HF. 1989. Global climatic anomalies associated with extremes in the Southern Oscillation. Journal of Climate 2:1069-1090.

DOI: 10.1175/1520-0442(1989)002<1069:GCAAWE $>2.0 . \mathrm{CO} ; 2$

Mestas-Núñez AM. 2000. Orthogonality properties of rotated empirical modes. International Journal of Climatology 20:1509-1516.

DOI: 10.1002/1097-0088(200010)20:12<1509::AIDJOC553>3.0.CO;2-Q

Preisendorfer RW. 1988. Principal component analysis in meteorology and oceanography. Elsevier, Amsterdam, $425 \mathrm{pp}$.

Reboita MS, Ambrizzi T, Rocha RPD. 2009. Relationship between the southern annular mode and southern hemisphere atmospheric systems. Revista Brasileira de Meteorologia 24:48-55.

DOI: $10.1590 / \mathrm{S} 0102-77862009000100005$

Rusticucci MM, Venegas SA, Vargas WM. 2003. Warm and cold events in Argentina and their relationship with South Atlantic and South Pacific Sea Surface temperatures. Journal of Geophysical Research 108, C11, 3356. DOI: 10.1029/2003JC001793

Silvestri G, Vera C. 2003. Antarctic Oscillation signal on precipitation anomalies over southeastern South America. Geophysical Research Letters 30, 21, 2115. DOI: 10.1029/2003GL018277

Wilks DS. 2006. Statistical methods in the atmospheric sciences (International Geophysics Series). 2nd ed. Academic Press, Burlington, MA, 627 pp. 